La fundación de un barrio: herramienta para pensar las bases antropológicas de la comunicación popular José Javier León Buitrago

Question, Vol. 1, N. 57, e018, enero-marzo 2018. ISSN 1669-6581

http://perio.unlp.edu.ar/ojs/index.php/question/article/view/4432

FPyCS | Universidad Nacional de La Plata

La Plata | Buenos Aires | Argentina

Recibido: 21-10-2017 Aceptado: 23-11-2017

Cita sugerida: León Buitrago, J. (2018). La fundación de un barrio: herramienta para pensar las bases antropológicas de la comunicación popular. Question, 1(57), e018. doi: https://doi.org/10.24215/16696581e018

\title{
La fundación de un barrio: herramienta para pensar las bases antropológicas de la comunicación popular
}

The foundation of a neighborhood: tool to think the anthropological bases of the popular communication

José Javier León Buitrago

Universidad Bolivariana de Venezuela (Venezuela) joseleon1971@gmail.com

\section{Resumen}

El artículo desglosa categorías que buscan explicar el proceso de fundación de un barrio (para el caso, El Renacer, ubicado en la periferia oeste de Maracaibo, estado Zulia, al occidente de Venezuela) con el fin de aportar elementos para pensar la comunicación desde una perspectiva antropológica. Revisa los orígenes del barrio, el sentido y el sentimiento de comunidad que tienen sus habitantes, la naturaleza de los conflictos que se presentan, las formas de apropiación de la tierra, de la vivienda y de los servicios y, finalmente, su consolidación. Los conceptos desde la teoría consultada buscan responder a la pregunta: ¿cómo se funda un barrio? En la respuesta se conjugan las definiciones de migración, ocupación de la tierra, 
organización para el asentamiento, la autogestión de los servicios, la autoconstrucción y en especial, la participación preponderante y crucial de la mujer. A ello se suman los problemas que se derivan de la nacionalidad, específicamente colombiana y la condición étnica wayuu. Las conclusiones describen formas de comunicación que hacen posible la sobrevivencia, la organización y la vida comunitaria.

Palabras clave: migración; comunidad; organización; autogestión.

\section{Abstract}

The article breaks down categories that seek to explain the process of founding a neighborhood (for the case, The Reborn, located in the periphery west of Maracaibo, Zulia State, Western Venezuela) in order to provide elements to think communication from an Anthropological perspective. Check the origins of the neighborhood, the sense and feeling of community that its inhabitants have, the nature of the conflicts that arise, the forms of appropriation of the land, of housing and services and, finally, its consolidation. The concepts from the consulted theory seek to answer the question: How is a neighborhood founded? The response conjugates the definitions of migration, land occupation, organization for settlement, self-management of services, self-construction and, in particular, the dominant and crucial participation of women. This adds to the problems that arise from the nationality, specifically Colombian and the wayuu ethnic condition. The conclusions describe forms of communication that make survival, organization and community life possible.

Keywords: migration; community; organization; self-management.

La investigación busca construir conocimiento sobre comunicación social a partir de las relaciones, formas y pautas de ocupación de los territorios, llevadas a cabo por sectores populares, específicamente en un asentamiento urbano periférico a la ciudad de Maracaibo. Se ubica en la necesidad de pensar un concepto que pueda percibir las diversidades culturales, pero sobre todo las relaciones que los sujetos van tejiendo para reconstituir la vida comunitaria. Para ello los sujetos emplean necesariamente una comunicación no prevista ni controlada, ni mucho menos agenciada por la mediática al uso. Esta comunicación periférica y subalterna basada en redes y vínculos, exige ser estudiada desde teorías que hagan énfasis en lo relacional, sin dejarse atraer por la retórica de las redes sociales vía Tecnologías de la Información y la Comunicación. 
Para desarrollar la investigación fueron precisas las herramientas de la etnografía, enmarcadas en la investigación cualitativa. La observación participante, las entrevistas no estructuradas, las conversaciones abiertas, las discusiones y anotaciones, produjeron un cuerpo de datos que, sometido a interpretación y análisis nos describe la forma de poblar un específico asentamiento urbano popular. Ello nos proporcionó las bases socio-históricas concretas para la redefinición de un concepto de comunicación alternativa a la producida por los medios del capital. Las entrevistas fueron organizadas en cinco dimensiones: La Fundación, El Campo de Relaciones, Las Dinámicas Internas, El Poder y La Comunicación, y analizadas con la técnica del Análisis de Contenido sustentaron las respuestas a siete preguntas: ¿Cómo se funda un barrio? ¿Cómo se construye la vida comunitaria? ¿Qué factores intervienen en el nacimiento y naturaleza de los conflictos que amenazan la vida comunitaria? ¿Cómo se construye la propiedad en el barrio? ¿Cómo afecta la consolidación urbana la vida comunitaria? ¿Qué elementos participan en la construcción del poder local? ¿Qué formas de la comunicación mediada e intermediada se manifiestan en la cotidianidad del barrio? El conjunto de los planteamientos tributó al planteamiento central: ¿Cómo se comunican relacionalmente, para la construcción de la vida comunitaria los habitantes de un asentamiento urbano popular?

La primera dimensión (La Fundación) es desglosada en las categorías: Migración, Ocupación, Organización fundacional, Autogestión, Autoconstrucción, Mujer y Nacionalidad. Fueron analizadas cinco conversaciones. Hechas las entrevistas procedí a su transcripción y en los textos subrayé fragmentos que llamé Frases Significativas de donde deduje Códigos que sintetizaban determinadas manifestaciones conceptuales. Entiendo por códigos:

\footnotetext{
palabras clave que sirven para hacer descripciones en un primer momento y posteriormente podrían utilizarse en la construcción de tipos. Es una abreviación o símbolo que aplicamos a unas frases o párrafos de las respuestas a una entrevista abierta, a notas de observación o a otras formas de registro (...) Con tales códigos o categorías se clasifican o codifican los datos. Pueden deducirse de preguntas de investigación o inducirse a partir de los datos (Rusque, 2003:160).
}

Los empleados, fueron agrupados por frecuencias y de acuerdo a su naturaleza, a los ámbitos que expresaban o recogían, se presentaron en conjuntos categoriales que permitían visiones cada vez más sistemáticas.

Hecho esto, se construyeron tablas de códigos agrupados por categorías que nos permitieron hacer una interpretación que arrojó consolidados interpretativos que sirvieron de insumo a los contenidos de las respuestas correspondientes a las preguntas de investigación que, finalmente, fueron formuladas para ordenar y exponer los resultados.

Detallando un poco más el procedimiento las entrevistas fueron transcritas y vaciadas cada una en tablas de renglones numerados, se procedió a una clasificación en torno a ideas, temas y 
conceptos en todo momento relacionados con el marco teórico de la investigación. Ello dio pie a una codificación, es decir a una transformación producto de procesos de descomposición y agregación bajo el criterio de pertinencia adaptando el material de análisis seleccionado y perteneciente al cuadro teórico elegido, a unidades que capturan una descripción general de dicha unidad de contexto.

Esas unidades son los códigos que, a su vez, son agregados por el mismo criterio de pertinencia a unidades mayores que funcionan como categorías. Luego, por medio de la inferencia, propia del Análisis de Contenido (Krippendorff, 1990) se procedió a describir, interpretar y comparar los códigos en los marcos categoriales establecidos de acuerdo a principios del análisis de contenido temático, que resume, define categorías y verifica la validez de los argumentos y de las conclusiones en el marco de un contexto multifactorial.

\footnotetext{
El análisis de contenido es una técnica de investigación destinada a formular, a partir de ciertos datos, inferencias reproducibles y válidas que puedan aplicarse a su contexto (...) Intuitivamente el análisis de contenido podría caracterizarse como un método de investigación del significado simbólico de los mensajes (Krippendorff, 1990: 28-30).
}

Las ideas obtenidas por inferencias (siempre considerando que "los datos que le proporcionan los sentidos obliga a un receptor a realizar inferencias específicas en relación a su medio empírico. A este medio empírico lo denominamos contexto de los datos" 1990: 31) alimentaron los contenidos de las respuestas a las preguntas de investigación que buscan hacer aportes al estado del conocimiento sobre la realidad estudiada, a saber, la comunicación en los sectores urbanos populares, relacionando y cruzando dentro del mismo trabajo, las definiciones de los expertos, los datos aportados por los informantes clave y por la teoría en marcos analíticos cada vez más amplios.

Valga recordar que, como afirma Krippendorff "los intereses y conocimientos del analista determinan la construcción del contexto dentro del que realizará sus inferencias" (1990: 37).

\section{Migración}

La migración, el desplazamiento de la población de una localidad a otra, con sus desgarramientos y no sólo sus desarraigos, es el drama contemporáneo por excelencia, el problema que mejor define la contemporaneidad. Se habla incluso de una "era de la migración" cuyos rasgos los define Soledad Álvarez (2011: 9): la globalización del fenómeno, la diferenciación (migración laboral, migración documentada, migración indocumentada, migración en tránsito, migración forzada), la aceleración y, muy importante, la feminización. 
En el caso que nos ocupa, la frontera colombo-venezolana ha sido considerada una de las más "calientes" del planeta, registrando un tránsito de cerca de 300 personas diarias, y un tráfico y contrabando verdaderamente problemático de diversos productos, de personas y combustible como de alimentos y drogas. El problema es histórico y por temporadas hace crisis.

Pero la migración no se registra sólo entre países vecinos, también es un problema interno, producto de desequilibrios históricos, acentuados en nuestro caso por un siglo de explotación petrolera. Los barrios y en el caso particular de El Renacer, son producto de verdaderos deslaves poblacionales indistintamente marcados por la pobreza. Como dice Pedro Trigo (2008: 121): "Los barrios no los forman comunidades vivientes sino gente de aluvión".

El fenómeno como lo conocemos mantiene una persistente unidad: se manifiesta en sujetos empobrecidos, con escasa calificación, con serias dificultades para obtener documentación adecuada, que traspasan fronteras -la mayoría de las veces de forma clandestina, víctimas de extorsionadores y traficantes- o se mueven de una ciudad a otra para asegurar un mínimo de subsistencia, aprovechando que familiares y amigos les ofrecen -a veces a regañadientes- un espacio para irse arrimando, acercando a la ciudad, a las oportunidades. Cuando vemos las terribles dificultades en las que llegan a vivir, pensamos necesariamente en las que dejaron atrás. Las oportunidades, sin embargo, aun en barrios como El Renacer compensan y permiten soñar un futuro mejor, una vida más digna.

(C.7-8) yo vengo de Colombia directamente por la cuestión económica que se da allá (C.10-11) pero usted sabe que algunas veces en casa ajena es mejor estar de visita (C.12-14) y de allí me vine para acá para Maracaibo a que una tía, con mi esposo y con mis hijos, colombianos todos, todos somos colombianos (C.22-23) yo conozco una parte por allá que están invadiendo, se llama Renacer (C.36-44) esto se limpia aquí y hacemos la casita, ya esto va a ser nuestro, me hizo ver las cosas desde otro punto de vista, y comenzamos a levantar la piecita aquí, semanalmente, compramos que si cien bloques, ya cuando terminamos la casita yo sentía que ya esto era mío, sin documento y sin nada pero ajá, cómo se hacía, y aquí gracias a Dios nos hemos quedado, estamos indocumentados y la casa está a nombre de mi suegro actualmente (C.57-60) Y yo me fui acoplando, cuando yo llegué aquí a la comunidad para allá no conocía, ya después me metí en el mundo de las asambleas de la comunidad, me di a conocer (C.6066) me gustó tanto el ámbito social, el roce con las personas, las asambleas, nunca había vivido eso en Colombia, y se llegó a dar un punto en que yo inclusive formé parte del consejo comunal, como contralora, y para qué, me fue bien, siempre quise hacer un trabajo transparente y a raíz de mi trabajo me di a conocer en la comunidad y aquí estoy...

Estamos frente a un fenómeno prácticamente no controlado, una situación creada por las presiones a las que son sometidas las personas por determinadas condiciones estructurales, que les hacen imposible la vida en los sitios donde nacieron o radicaron. No creemos que se trata de una mera movilización social producto de un efecto modernizador; viendo la marginalidad desde una perspectiva histórica, la ocupación ilegal de tierras puede llegar a ser 
"normal", una forma "más que excepcional de tenencia de la tierra, ya que los ocupantes ilegales constituyen una primera avanzada hasta su posterior consolidación por medio del acceso a la propiedad y el reconocimiento final de titularidad" (Spicker y otros, 2009: 217). Eso persiste en el caso venezolano, sobre todo desde el momento en que el Estado bolivariano (desde 1999 hasta hoy) reconoce la condición de debilidad y necesidad y en consecuencia ha instrumentado leyes que favorecen a los ocupantes.

Reza el artículo 1 de la Ley especial de regularización integral de la tenencia de la tierra de los asentamientos urbanos populares:

La presente Ley tiene por objeto ordenar y regularizar el proceso de la tenencia de la tierra, ocupada por la población en los asentamientos urbanos populares, y contribuir a la satisfacción progresiva del derecho a la vivienda y el hábitat, dando prioridad a la familia, especialmente a aquéllas en condición de vulnerabilidad social, y así consolidar los asentamientos urbanos populares ya existentes, de manera digna, equitativa y sostenible, mediante un proceso de cogestión integral con el Estado (2006).

Bajo el enfoque histórico-estructural el fenómeno deja al descubierto la conformación de una sociedad capitalista que genera centros de atracción y periferias expelidas. En el caso que nos ocupa hay que sumar la violencia política, social y paramilitar que se cierne sobre la población campesina, afro e indígena en Colombia:

En Colombia la aceleración de los niveles de violencia desde la segunda mitad de los setenta, la agitación laboral con ese punto álgido representado por la huelga general de trabajadores en septiembre de 1977 y la puesta en vigor un año después, del llamado 'estatuto de seguridad' del gobierno de Turbay Ayala, contribuyeron al dinamismo de los flujos migratorios de la época y su primer y más importante destino: Venezuela (Gómez, 2008: 35).

Ese flujo no ha cesado y los distintos gobiernos que por ese país han pasado han incrementado las políticas de "seguridad" contentivas de altas dosis de terrorismo de Estado.

Históricamente, el fenómeno de la migración ha estado presente en las relaciones colombovenezolanas, pero su motivación estuvo principalmente influenciada por causas económicas. Sin embargo, la agudización de la crisis política y el conflicto armado que vive Colombia desde el siglo pasado, está agravando la radicalización y degradación de los movimientos migratorios, originando esto el desplazamiento interno (Colombia) y a una migración forzada hacia los países vecinos (Álvarez, 2004: 198). 
Es cierto que los migrantes tienden a trabajar en oficios despreciados por los naturales, albañiles, vigilantes, braceros, etc., pero no se puede decir que exista una planificación económica por parte de las autoridades venezolanas para contar con esta población, no al menos en una ciudad como Maracaibo, aunque no lo descartamos en el Táchira o en el Sur del Lago, específicamente en zonas agrícolas y pecuarias. El hecho, sin embargo, es que ocurre y genera distorsiones que la dinámica social y económica hace llevadera, sin mayores nudos críticos. En efecto, difícilmente exista entre las clases populares un sentimiento de xenofobia o racismo que conduzca a situaciones de violencia; al contrario, ha habido una fusión que torna indistinguibles las raíces y las manifestaciones criollo y wayuu colombo-venezolanas.

\footnotetext{
¿Cómo es posible discriminar a los trabajadores colombianos, allí donde no hay diferencias apreciables en materia cultural, lingüística, religiosa, ni de raza? Si por el contrario, comparten una identidad cultural que trasciende la frontera, entonces, ¿cómo diferenciar un wayúu en la Guajira? ¡Si hasta portan las dos cédulas de ciudadanía, colombiana y venezolana! (Gómez, 2008: 35).
}

Valga destacar que existe un reconocimiento y reivindicación de las culturas wayuu y colombianas, fruto de la dinámica política y cultural que pone el acento en la diversidad y que ha facilitado acercamientos, propiciado el diálogo y motivado -como en este casopreocupaciones académicas.

A continuación, las categorías donde se va de lo general a lo particular, con el fin de buscar comprender cómo influyen los diversos factores socio-históricos en la cotidianidad de las familias fundadoras, cómo resulta vital la comunicación relacional y fundamentalmente, cómo sus mecanismos deben ser recreados a la hora de emprender proyectos de comunicación popular que consideren a estos sujetos actores y protagonistas, no meros consumidores pasivos.

\section{Ocupación}

Entendemos aquí por ocupación los aspectos relacionados a los asentamientos populares urbanos llevados a cabo por una poblada con necesidad de vivienda. Los llamados "Sin Techo" son personas sin hogar, que viven hacinados en casas de familiares y que a la mínima oportunidad se aventuran a la ocupación ilegal de tierras en donde hacerse de una parcela y levantar una casucha.

El término "sin techo" también se utiliza para indicar que las personas no tienen un hogar propio. Es así entonces que se puede tener alguna forma de vivienda -como alojamiento en 
albergues $u$ hospedajes temporales con amigos o familiares- pero, a pesar de ello, no tener un hogar (Spicker y otros, 2009: 270).

Han sido calificadas de manera diversa: villas miseria, asentamientos, favelas, ranchos, entre otras denominaciones y son características de la mayoría de las ciudades del llamado Tercer Mundo. Como dice Connolly el asentamiento irregular

empezó a dominar la producción de vivienda a bajo costo a partir del segundo tercio del siglo pasado. Barriadas, favelas, pueblos jóvenes, barrios, barrios de rancho, barrios populares, lotificaciones irregulares, asentamientos humanos auto-producidos, asentamientos urbanos (o humanos) irregulares, populares, no-controlados o precarios, colonias populares o proletarias, villas miseria, callampas, urbanización informal, fraccionamientos clandestinos, piratas, urbanización popular... (s/f: 8).

(A.12) siempre tenemos que depender de otro... (A.62-65) Cuando yo llegué aquí aquí no había nadie, esto lo invadimos nosotros, esto va para nueve años... (A.80) Empezaron a decir que había una invasión... (A.83-86) Estaban invadiendo ya, hacían reuniones, que va a haber la invasión, que van a repartir los terrenos, que van a dividir, nosotros veníamos a las reuniones, después empezaron a dar los terrenos (A.88-89) Por aquí. Tenía Anni... ella las tenía cuando eso, fue quien entregó los terrenos... (A.89-91) empezamos a ir parando con latas, después nos metimos así, monte y monte y monte y monte hasta que empezó la gente a parar también (A.91-93) Tenía Anni... ella las tenía cuando eso, fue quien entregó los terrenos... (A.96-97) gracias a Dios estamos poco a poco, uno va arreglando las cosas... (A.118-199) Desde que llegamos nosotros para acá todo se quedó quieto, por eso que se funda el barrio en el 2004 (A.134) Me ayudó el marido de una tía mía (A.139) iy con miedo, oíste! (A.143-144) estaba invadiendo un terreno que no era mío, sería un poco de temor, pensaba que me iban a fregar (A.146147.149-150) No, y él no quería... él no quería ¡no que tal! Yo agarré mis latas y me vine (risas de ella) él no quería... No venía para acá porque le daba miedo, yo vine y traje mis chécheres...

Como rasgo común encontraremos que se trata de una "invasión "espontánea" o concertada de espacios vacíos existentes en la periferia del casco urbano, generalmente de propiedad pública y en menor escala privada; que en ella participan grupos de familias de bajos ingresos económicos, en su mayoría procedentes de áreas rurales con una cultura "tradicional"; que tienden a organizarse a fin de actuar solidariamente para el logro de un lote y la obtención de servicios básicos y facilidades comunales" (Connolly, s/f: 8). Con respecto a El Renacer estamos en presencia de un barrio periférico surgido de una manera informal al oeste de la ciudad de Maracaibo.

Los estudios señalan que, en las últimas décadas, en la generalidad de los países no existían planes serios ni masivos de construcción de viviendas populares por parte del Estado, de modo que la proliferación de barrios se convirtió en una característica del subdesarrollo. 
En nuestro país y en particular, recientemente con la Gran Misión Vivienda Venezuela se busca incidir de manera estructural en el problema, y por la dimensión del esfuerzo gubernamental y el conglomerado de actores del Ejecutivo y organismos oficiales, incluso empresas extranjeras (de Irán, China y Bielorrusia, entre otros países) que gestionan proyectos de construcción, nos podemos hacer una idea del andamiaje institucional que se requiere para acometer una obra social de tal envergadura, casi una suerte de Plan Marshall tropical, diseñado e impulsado por el presidente Hugo Chávez para saldar una deuda social producto de un siglo de capitalismo dependiente, colonial y, en las últimas décadas del siglo XX, neoliberal.

Tanto para el Estado latinoamericano tradicional como para el Mercado, las viviendas y las formas de vida en general corren por cuenta de la población, de ahí las masivas ocupaciones acompañadas de ingentes esfuerzos de autoconstrucción. Con algo de ironía De Lomnitz afirma que: "La barriada (...) contribuye a la economía nacional al resolver un problema habitacional que ni el gobierno ni la empresa privada han logrado enfrentar" (2006: 35).

Como rasgos comunes generales encontramos:

Ocupación ilegal de terrenos que se encuentran en propiedad pública o privada;

Compra de pequeños terrenos (en promedio de 100-150 $\mathrm{m}^{2}$ ), en gran parte por supuesto sin la correspondiente transferencia de propiedad en el registro de la propiedad;

Construcción (y consolidación posterior, es decir remodelación y ampliación) sin permiso de construcción que incluye también la pregunta de si allí se debe o no construirla no consideración de normas de construcción (estática, materiales de construcción, cantidad de pisos, distancia, conexiones a infraestructura, etc.);

Construcción en autoayuda que se ha transformado para todos los estados casi en parte normativa de la obtención de viviendas y de mejoras para las clases sociales bajas y a través de las cuales se evitan los considerables gastos públicos para los programas de construcción de viviendas correspondientes (construcción de viviendas sociales) (Mertins y otros, 1998: 5-6).

Obviamente estas "ocupaciones ilegales carecen de una infraestructura básica mínima servicios públicos como electricidad, agua corriente, sistemas sanitarios y recolección de residuos- y la mayoría de estas viviendas son precarias" (Spicker y otros, 2009: 217). La descripción para uno acaso funcione para todos:

Aun en el caso de que un grupo de personas se haya puesto de acuerdo para invadir un terreno, ordinariamente mediante un intermediario, esas personas no eran entre sí vecinos ni parientes ni amigos ni siquiera conocidos. Fueron contactados y emprendieron juntos esa aventura de conseguirse un lote de terreno para edificar un ranchito. Cada quien busca su propia casa, pero invadieron a la vez porque es el único modo de resistir cuando los quieran desalojar, porque la unión hace la fuerza. Por lo mismo se unirán para construir escaleras o 
pasajes o calles y para demandar y meter los servicios básicos; es decir para realizar lo que les incumbe a todos y sólo en conjunto pueden llevar a cabo (Trigo, 2008: 121).

Valga sin embargo citar la descripción de Cerrada del Cóndor, barrio similar a El Renacer (con ese "aire de familia" que tienen los barrios pobres latinoamericanos), hecha por la antropóloga chilena-mexicana Larissa A. De Lomnitz:

No existe pavimentación, alcantarillado, agua corriente (con excepción de siete viviendas), instalación eléctrica, teléfonos, recolección de basura, alumbrado público, ni drenaje de aguas Iluvias. En general no hay servicios urbanos básicos (2006: 40).

\section{Organización fundacional}

Por organización fundacional entendemos las relaciones de comunicación para lograr acuerdos conducentes a la ocupación de un lote de tierras y a la consolidación del asentamiento urbano popular. En la organización encontraremos activas redes de intercambio que "suplen la carencia de seguridad y actúan como mecanismo de seguridad social” (De Lomnitz, 2006: 99). Invariablemente se requerirá un contacto, familiar o conocido, ya en el lote o cercano a él, que hace de puente y ofrece algo de confianza y sustento durante los momentos más duros sobre todo los del inicio de la ocupación.

El necesitado de un lugar donde vivir se desenvuelve en el ámbito de los grupos sociales excluidos, en los cuales podrá enterarse de la existencia de un lote que puede ser ocupado. Esto, más el familiar o el conocido, deciden e impulsan al ocupante. Si se carece de la segunda premisa, la ocupación se hace mucho más difícil y sin duda más traumática.

En los primeros días, cuando no es posible pensar en nada estable, cuando se está luchando apenas para lograr la parcela, y si además se tienen hijos, el contacto con los familiares es vital. Pero si estos viven lejos, pronto se necesitarán conocidos al interior del barrio o a lo sumo, lo más cerca posible, de modo de aliviar desde el hambre y la sed hasta un hilo de agua o electricidad.

Estas particularidades se tornan generalidades, como parte de una pauta de migración y ocupación de la que ya hemos hablado. Nos importa aquí, sin embargo, resaltar los mecanismos de comunicación descritos desde las relaciones, que suponen redes de intercambio para la sobrevivencia, pero también de comunicación popular de la cual habría que recuperar sus valores formales y estructurales. Esas redes de comunicación nos hablan de espacios e intersticios que no aparecen en los mapas de la sociedad integrada. Los barrios se convierten en espacios sociales más amplios que actúan como mediadores, 
entre el mundo privado de la casa y el espacio público de la ciudad. El barrio proporciona a las personas elementos para la construcción de una sociabilidad más ancha que la fundada en los lazos familiares y a su vez más profunda y duradera que las relaciones formales e individuales que impone la sociedad" (Ametrano y otros, 1995: 15-16).

Desde esta perspectiva las realidades sociales, económicas, culturales que producen los barrios hacen parte de una realidad no vista ni comprendida por la racionalidad oficial y académica, pero que no obstante forma parte de casi la mitad de la población de un país como el nuestro.

De modo que, cuando hablamos de la organización fundacional, la cual se da al interior de los procesos de migración y ocupación y que conducen a la estabilización del asentamiento urbano, hablamos de las estrategias de relacionamiento que les permite a los ocupantes alcanzar el objetivo de fundar un nuevo barrio. Estas estrategias están articuladas a redes migratorias conformadas estructuralmente por parientes, familiares, conocidos, que han logrado avanzar al interior del país (en el caso de los migrantes colombianos) pero, sobre todo, al interior de las ciudades con sus promesas de mejores condiciones para la vida.

(D.555-568) Para mi estar en Renacer es y ha sido prácticamente mi vida, yo rodé mucho, con mis hijos, llevé mucho mucho de parte de mis dos familias, que es la familia de mi esposo y mi familia, yo viví con mi mamá y no fue nada fácil, viví con la mamá de él y mucho menos, viví alquilado muchísimo tiempo, viví arrimada en casa de tíos, mi cuñada mucho tiempo y al yo tener este terreno o sea yo decía que al yo tener este terreno que iba a ser mío, ya nadie me podía sacar de acá, Yo iba a mandar en él, por eso es que cuando me llagan a invadir yo me pongo como una gata, me entiendes, porque yo decía no, si esto es mi vida, y aquí estoy, y mi Presidente ahora me hizo una casa, me cambió un rancho y me dio una enorme casa hermosa bella y preciosa.

Las relaciones se cultivan en espacios de trabajo precario y provisional, móvil, sin arraigos, inconsistentes, propios de y para personas que no saben a ciencia cierta donde estarán en los próximos días. El hombre, con mayor movilidad, se mueve en estas capas del trabajo informal como vendedor, limpiador de parabrisas, en el mejor de los casos como albañil, mientras la mujer aguarda y presiona con insistencia para convencerlo de la imperiosa necesidad de encontrar un espacio para levantar una vivienda. El miedo atenaza, pero la necesidad es resolutiva.

El hombre va de trabajo en trabajo, relacionándose con personas que, como él, pueden estar buscando donde fundar un asentamiento. Hallado el lugar y hechas las primeras gestiones para levantar la vivienda, la mujer cobra centralidad y organiza la resistencia para la vida. En efecto: 
Son las mujeres las que realizan tareas en torno a las organizaciones comunitarias, en donde se interrelaciona el hogar y problemas con aquellos del barrio, y que a pesar de las dificultades que esto plantea, encuentran estrategias apropiadas para conciliar estos dos espacios, que en lo cotidiano se superponen y conectan constantemente (Clavijo, 1995: 29).

Estas "estrategias apropiadas para conciliar" y concertadas para vivir que apuntan a la estabilización y consolidación, le dan el tono a la organización fundacional. Como lo refiere Ontiveros y De Freytas (1996) los barrios viven "in extenso las relaciones de espacialidad, socialidad y cotidianidad":

...en estas comunidades la relación del habitante con sus espacios interiorizados es mucho más densa, el afecto, la solidaridad, etcétera. Puede que en algunos se observe la "maximización del colectivismo" y que en otros casos se matice, pero hay una disposición a que se mantenga un sentido de solidaridad en los momentos más acuciantes del barrio (Ontiveros y De Freytas, 1996: 130).

El barrio es el resultado de "simbiosis societales" observables, dice Ontiveros y De Freytas (131) a través de "estrategias y modos de vida que escenifican en la trama del vivir diario los habitantes de los barrios (...) el barrio constituye redes de relaciones". Estas redes suponen asociaciones que responden a la dinámica de "una o varias familias concertadas, de un grupo de amigos, de unos compadres o de unos vecinos comprometidos:

\footnotetext{
Empero, la organización popular no es un proceso pasivo dentro del sistema de grupos primarios de la comunidad; también desde la experiencia de la organización popular se produce y reproduce el parentesco real o ficticio (compadrazgo), la amistad y la vecindad. Tal resultado social activo significa que el proceso del grupo primario llega a ampliarse y a consolidarse mediante la reconfirmación del proceso organizativo comunal. Todo ello ocurre, no obstante, como en la superficie. Si nos acercamos más al problema y vamos al fondo de la cuestión, podemos concluir que la asociación sociopolítica popular tiene siempre como soporte la dinámica fundamental de la familia extensa modificada, y ello se canaliza en los intereses del grupo así estructurado... (Hurtado, 1996: 123).
}

En conclusión, la organización fundacional condensa la síntesis de las relaciones de los diversos actores familiares, vecinales, de amigos y conocidos, en función de la ocupación, estabilización y consolidación del barrio.

\section{Autogestión}


Podemos considerar el que sigue como un concepto más o menos convencional: "Sistema de organización social, política y económica de un colectivo de un determinado ámbito, mediante el cual éste tiene la autonomía para establecer los lineamientos sobre la producción, manejo de recursos, elaboración de normas, planificación y diseño de planes de desarrollo integral endógeno" (Ojeda, 2010: 73). Pero el que nosotros necesitamos debe compartir su alcance con el de autoproducción, determinante sin duda alguna en la generación y producción de la vida en el barrio.

Conservamos sin embargo el concepto de autogestión porque axiológica y teleológicamente persiste la relación de la autoproducción del barrio como germen para un proyecto de emancipación que tiene base en estas organizaciones.

Como lo hemos dicho, nacen los barrios a partir de una violencia desarraigante, que conduce a las personas en medio de unas circunstancias verdaderamente extremas a acordar y juntar esfuerzos para marcar como objetivo de ocupación un lote de tierras. Con la pobreza a cuestas y con recursos mínimos levantan viviendas y tienen, además, la fuerza y la voluntad política para llevar a cabo acciones que modifican sustancialmente el territorio, el "nicho ecológico" como dice Larissa A De Lomnitz, y con suerte y mucho esfuerzo, logran estabilizar el asentamiento e impulsan desde ese piso conquistado su consolidación. Todo ello lo alcanzan activando su capital social (en los términos de Bourdieu), autoproduciéndose como verdaderos sujetos políticos, solo que desde una política no legitimada por la academia y en muchos casos subvalorada por los actores políticos hegemónicos o estatales.

Por estas razones prefiero hablar de autogestión, aun cuando no se planteen estos sujetos, con la coherencia y la solidez del caso y tensionados por las necesidades más apremiantes, "la producción, manejo de recursos, elaboración de normas, planificación y diseño de planes de desarrollo integral endógeno". De haber un futuro posible, sólo en estos momentos fundacionales tendrá raíz y posibilidad.

La autogestión entonces la entenderemos como la capacidad que tienen los sujetos de barrios como El Renacer para re-producir su vida, activando el capital social y económico que poseen. La autogestión es la re-productora de la vida en el barrio, está llena de pasado, de experiencias anteriores vividas o no por los propios sujetos, pero sin duda, que forman parte de la memoria social de un pueblo que ha tenido que autoproducir sus condiciones materiales sobre la base histórica de una subjetividad en resistencia. El habitus es la condición "no sólo de la concertación de las prácticas sino también de las prácticas de concertación" (Bourdieu, 2007: 96).

\section{Autoconstrucción}


Posiblemente las actividades que concentra esta palabra contienen el pasado, el presente y el futuro de los sujetos que ocupan el asentamiento urbano popular. Sin haberlo hecho antes, aprenden a levantar la vivienda, aprovechando el conocimiento de los vecinos y activando los suyos propios, nacidos de la necesidad más apremiante.

Se construye la vivienda para resistir a la intemperie, para decirle a las autoridades que se está decidido a vivir en el lugar y para darse y darle confianza a los suyos. Se construye la vivienda para la vida, contra las inclemencias de la naturaleza y con la esperanza de que los materiales sean firmes, resistentes, no perecederos. En la construcción de la vivienda confluyen todos los tiempos y es el acto fundacional por excelencia, personal y colectivo:

La casa obviamente es autoconstrucción. Y aquí viene el soñar y el aprender. Imaginar qué es lo que quiero y capacitarme para hacerlo posible y realizarlo. La obsesión permite soñar: al abrir el campo de lo posible le lleva a uno a dibujar en él su sueño, a acariciarlo, a perfilarlo cada vez más, pues es una libertad situada (Trigo, 2008: 82).

El concepto de autoconstrucción se refiere al fenómeno de los poblamientos no planificados por el Estado caracterizados por viviendas construidas y habitadas por sus propios habitantes. Autoconstrucción es construcción al ritmo de las posibilidades y necesidades de los usuarios: la vivienda va creciendo progresivamente de acuerdo al presupuesto familiar, aunque difícilmente se solucione el hacinamiento. Las viviendas son por supuesto auto-diseñadas, se emplea la autogestión y autoayuda y en lo posible los bancos colectivos de materiales.

(C.36-44) esto se limpia aquí y hacemos la casita, ya esto va a ser nuestro, me hizo ver las cosas desde otro punto de vista, y comenzamos a levantar la piecita aquí, semanalmente, compramos que si cien bloques, ya cuando terminamos la casita yo sentía que ya esto era mío, sin documento y sin nada pero ajá, cómo se hacía, y aquí gracias a Dios nos hemos quedado, estamos indocumentados y la casa está a nombre de mi suegro actualmente

Hay que apuntar sin embargo que la autoconstrucción sobre todo en las grandes urbes es expresión de la violencia que el sistema capitalista ha ejercido sobre la población forzándola a abandonar las tierras productivas y ancestrales, por las empobrecidas y difíciles al margen de las ciudades. Autoconstrucción que no responden a un plan y a una determinación política y estratégica en función de una economía integral, sino que es respuesta material a la exclusión. Lejos de una laudatoria celebración de esta habilidad de los sectores populares, enfocamos su existencia como acervo cultural de la resistencia, el cual será útil a la hora de las reivindicaciones políticas de las formas de vida y de cotidianidad que los sectores populares se dieron en su desarrollo histórico. 
Es cierto que por muchos años y en buena parte de los análisis sociológicos pocas veces se reconoce la autoconstrucción por los sectores populares. La invisibilización es producto, como ya lo analizamos en su momento, de paradigmas que parten del no reconocimiento del otro. Luego, cuando el otro producto de sus luchas comienza a hacerse visible entre movimientos de flujo y reflujo que logran que el capital sometido a las presiones populares consienta, aproveche y luego de nuevo rechace estructural y sistemáticamente los aportes populares, el autoconstrucción es aprovechada por la modernización de los años 50 y 60 por un Estado que no tenía capacidad para desarrollar la urbanización que requería para sus planes de expansión. De modo que abrió las compuertas de la ocupación ilegal y el autoconstrucción consintiendo la creación de lo que aquí se llamó los "cinturones de miseria".

La explosión migratoria y las oleadas de "invasiones" serían luego controladas con abundante represión sobre todo en los ochenta (los barrios recibían el nombre de acuerdo a las batallas ganadas a la policía y a la Guardia Nacional: El Esfuerzo, Los Planazos, La Conquista, El Renacer...) y de cuando en cuando, al ritmo del asistencialismo y el populismo, políticas de urbanización popular eran destinadas a mermar reclamos: "soluciones habitacionales", esmirriados planes de viviendas compuestos regularmente de casas de muy bajo presupuesto.

\footnotetext{
...constituye todo un reto superar las distorsiones existentes en la configuración del espacio urbano contemporáneo, traducidas mayoritariamente en una clara y preponderante segregación espacial, expresada físicamente en una importante proporción de la población urbana viviendo en asentamientos precarios e inestables, la cual no fue suficientemente atendida por los planificadores venezolanos sino hasta principios de la década de los noventa (Ornés, 2009: 219).
}

Con todo, las ocupaciones ilegales se plegaban a los ritmos políticos electorales hasta que, recientemente (la vivienda 1 millón 800 mil fue entregada en octubre de 2017) se diseñó y activó un plan masivo de construcción de viviendas (Gran Misión Vivienda Venezuela) -y por ende de regularización de la tierra- en el que participan todos los entes y organismos del Estado, en un esfuerzo gigantesco que indirectamente nos explica por qué no se asumen planes de esta magnitud en otros países con una vocación social menos marcada o nula.

\section{Mujer}

Por las mujeres pasa la fundación del barrio, la autoconstrucción, la organización, el sentido de comunidad y todo cuanto hace posible la vida en el barrio: "las mujeres están dando el tono en el barrio, en la cultura del barrio, no sólo porque en ella son mayoría sino porque le dan otro sesgo distinto, fundamentalmente biófilo, que busca tender puentes, resolver conflictos, 
componer niveles diversos de realidad, construir, de modo que el proceso de la vida siga y fluya y las personas tengan cada una su lugar en ella" (Trigo, 2008: 130). Las mujeres sostienen invariablemente el hogar y son el corazón de las familias. No obstante, sufren de manera más directa los embates del desarrollo pues la pobreza sin duda está feminizada: "Las mujeres soportan una parte desproporcionada de la carga de la pobreza, y los niños que crecen en esa situación suelen quedar en desventaja para siempre" (Spicker, 2009: 236).

La mujer en el barrio es multilateral.

(C.473-475) Sí, bueno, él es colombiano pero ya tiene años aquí en Venezuela, eso lo vine a saber ya después viviendo acá, como dicen por allí la sangre llama (risas) (C.499-508) Y él hizo un préstamo allá, habló con la dueña para comprar unas láminas, salió más temprano, pidió el siguiente día libre, compramos las láminas y comenzamos a montar el techito, ya con el techito le dimos otra vida a la casa, es más mi esposo pensaba armar la casa como un cuadro, yo le dije no, un cuadro es muy feo, hacerlo en forma de casita, y como vamos a hacer con las láminas, las doblamos, eso que ves aquí con forma de casita ha sido idea mía, él nomás construye yo le doy la idea (risas) yo soy la ingeniera...

La mujer atiende a la casa y a la familia, incluso si trabaja fuera. Participa en las organizaciones políticas, religiosas y en otras, de manera simultánea. Otras, sólo se dedican a ayudar y colaborar. Sin abandonar el lavado, la cocina y el cuidado de los niños, soportan la presión de los embarazos con el consumo de energía y fuerzas que supone. La mujer ha tomado la palabra en el barrio: en las organizaciones tienen preponderancia y en muchas tienen cargos de dirigencia. "Un reto -dice Pedro Trigo- es cómo transitar de lo doméstico a lo público sin perder la cotidianidad" (2008: 108).

En los desequilibrios provocados por el modo de producción social, con una división del trabajo marcadamente patriarcal, la mujer recibe la peor parte. El paradigma patriarcal ha sido antropocéntrico y, consecuentemente, androcéntrico. Basado en la idea de dominio sobre la naturaleza y sobre los seres humanos, se hizo extensivo a las mujeres, de ahí que sus trabajos se entendieran como "improductivos" porque consisten básicamente en producir y reproducir vida. El modo de producción del trabajo doméstico produce valores de uso que se consumen en la familia y no pueden ser vendidos como mercancías puesto que estrictamente no lo son. Las mujeres han tenido menos posibilidades que los hombres para convertir su trabajo en ingresos.

No obstante, la mujer forma parte ya de otra forma de comprender el mundo; si el mundo del trabajo sigue operando de acuerdo a los valores impuestos por el patriarcalismo, es indudable que en el barrio y en la construcción de la vida en comunidad, la voz masculina ya no copa el espacio. Ello indica que, en la construcción de otra economía y, por ende, otra comunicación, la mujer tiene mucho mayor espacio de incidencia, y posiblemente, sólo sea posible si ella y sólo 
cuando ella, participe. Hablando Enrique Dussel de Rosario, personaje de una novela de Alejo Carpentier, desarrolla lo siguiente:

\begin{abstract}
Una economía erótica meta-físicamente humana es la expansión plena del inconsciente, servicialmente pro-ductor de nueva realidad, no como una mera actividad lúdica romántica, sino como construcción de la casa y en ella inventando y colocando el fuego, como fabricación del vestido para la inclemencia de los climas, como cosecha y procura del alimento para reparar las energías y poder así vivir la proximidad erótica de la pareja (Dussel, 2007: 91-92).
\end{abstract}

La nueva economía y la nueva comunicación portan los llamados "valores femeninos": el cuidado, la solidaridad, la paciencia, la no violencia, incluso la ternura, la resistencia y más aún, la resiliencia, esa extraordinaria capacidad que tiene la mujer para sobreponerse a los dolores y a los traumas. La economía y la comunicación otras, sin duda feminizadas tienden a la construcción colectiva de la felicidad, y se edifican sobre conocimientos informados por las emociones y los sentimientos, antes que por la razón técnica instrumental desafectada.

\title{
Nacionalidad
}

Se incluye este concepto dada la composición poblacional del barrio El Renacer, y en general por la numerosa presencia de colombianos y colombianas en los barrios periféricos de la ciudad de Maracaibo: "Para 1980, los colombianos en Venezuela representaban el $77 \%$ del total de migrantes intracomunitarios, y en 1990, el 76\%" (Álvarez, 2004: 194). Como tal, los migrantes colombianos delinean el perfil de la población, e intervienen activamente en lo económico, lo político y cultural.

Por otro lado, enfatizamos la relación "nacionalidad colombiana" porque el wayuu no se plantea seriamente este conflicto pues ha logrado ganarse el derecho a portar una identificación fronteriza que le otorga libertad en sus itinerarios. La etnia wayuu legalmente y por derecho consuetudinario goza de doble nacionalidad.

(A.179-180) Yo no tengo familia aquí, en familia todas en Colombia... (A.188-189) vivimos sin luz, cocinábamos con leña... (A.193-196.199-200.202) Gracias a Dios tenemos gas, el agua (Nos alumbrábamos con velas...) porque la hemos puesto contrabandeada, por eso que tenemos eso, si no tampoco tuviéramos eso... De allá del barrio ese, peleando, luchando ahí con la gente. Sí, para que la gente no nos molestara (A.221-222) Todo esto era confusión... aquí no se sabía dónde era la casa... (A.238-240) Los dos mayores tuve que enviarlos para Colombia porque le estaban pidiendo los papeles en el colegio... 
La conflictiva es, entonces, la colombiana. El Estado venezolano en su política de recepción de los refugiados implementó la Ley Orgánica sobre Refugiados o Refugiadas y Asilados o Asiladas (2001) y su Reglamentación (2003), además, el nombramiento de la Comisión Nacional de Refugiados (2003) y la propuesta de creación de Comisiones Técnicas Regionales para los mismos fines. Dicha normativa legal sitúa a Venezuela a la vanguardia de los países garantes de los derechos humanos y del Derecho Internacional Humanitario. Valga mencionar que entre 1988 y 1998 se otorgó la nacionalidad a cerca de veinte mil extranjeros, pero ya en 2004 cerca de 250 mil la habían recibido, lo cual es un indicador de la voluntad del Estado bolivariano de solucionar el problema, saldar una deuda social adquirida por un problema externo, y dignificar las condiciones de vida de una población que huyó y huye del conflicto, como lo siguen atestiguando movimientos de pobladores recientemente desplazados a pesar del discurso oficial por parte del Estado colombiano de que ha cesado la violencia.

Pero estar a la vanguardia no significa que los problemas aguas abajo, a ras de la población vulnerable, que escapa de la violencia económica, social, paramilitar, se solucionen con la justicia y la celeridad que ameritan los casos, salvando claro está los niveles crecientes de complejidad.

El punto es que la nacionalidad colombiana sufre los problemas de carecer de un régimen fronterizo claro, minado además por una guerra interna de más de medio siglo y que arreció en los años ochenta. Como respuesta popular a esta violencia se establecieron redes sociales fronterizas con conexiones en buena parte del país, que garantizan un flujo ininterrumpido de migrantes. La relativa facilidad torna el problema inasible, los límites comienzan a desdibujarse y la necesidad natural de identidad que le permita al refugiado y al migrante en general gozar de los derechos que ofrece el país receptor no puede ser satisfecha sino con medidas extraordinarias, de corto aliento y lejos de resolver lo estructural.

\footnotetext{
El carácter permeable que adquiere la frontera, más la existencia de redes sociales, garantizan la entrada de ciudadanos colombianos a territorio zuliano de manera permanente y rutinaria. Todo esto incide en el crecimiento descontrolado del medio urbano (Yicón y Acosta, 2009: 161).
}

Sin duda la intensa movilización política que ha sido un rasgo característico de la última década facilitó e incentivó en los asentamientos urbanos populares la participación de colombianos y colombianas, esto unido a la política migratoria del Estado protector garante del derecho a la identidad. Pero la definición de Nación por parte del Estado es una cosa, otra la vinculación con los territorios de origen y la respectiva nacionalidad de los migrantes.

Ese factor juega un importante papel en la dinámica social de los barrios porque logra algo que, aunque es natural reviste de atención: la reafirmación cultural de la diversidad, la afirmación de 
la extranjeridad, parte a su vez de los efectos de una suerte de nacionalidad líquida -para decirlo con un adjetivo de Zygmunt Bauman (2004)- como uno de los productos de la globalización. Más que identidad hablaríamos de identificación, un esfuerzo por encontrar una imagen y una afirmación en medio de todo lo perdido. La identificación "es un sucedáneo de lo colectivo" afirma Héctor Díaz Polanco (2008: 142), pues permite sentirse parte de una comunidad desplazada, descentrada, sin lugar ni territorio, pero que se hace idea con los restos ( $\mathrm{t}$ )raídos de la cultura de origen hasta donde alcance a imaginarse y recordarse.

\section{Conclusiones en clave de comunicación}

La migración es imposible sin redes de solidaridad, pero también, sin la activación de mecanismos opacos o invisibles para la racionalidad de los Estados, de sus instituciones y organizaciones. La comunicación entre los migrantes y las redes que facilitan el movimiento en la frontera y luego, el proceso de reubicación en las periferias de las grandes ciudades, supone estrategias de comunicación dirigidos a garantizarles la vida, la supervivencia de los grupos. Familias dispersas sin embargo conectadas en puntos sensibles o coyunturales por organizaciones alternativas que pueden incluso permanecer invisibles por razones de seguridad. Se trata de familias y organizaciones transfronterizas y de alguna manera transestatales, redes de intercambio para la sobrevivencia.

Son "estrategias apropiadas para conciliar" y concertadas para vivir que apuntan a la estabilización y consolidación. El barrio está hecho de redes de relaciones.

Lo que hacen se confunde en este nivel con una comunicación no oficial hecha por el pueblo (y de ahí su carácter "popular") de la cual este artículo propone recuperar sus valores formales y estructurales. Esas redes nos hablan de espacios e intersticios que no aparecen en los mapas de la sociedad integrada, que rebasan las connotaciones políticas estatales y están constituidas por prácticas cotidianas que reproducen intercambios no mediáticos y no mediados, situados en la base de una intersubjetividad para el uso político, organizativo y educativo de una población que día a día lucha por llevar su vida adelante. Los grupos que integran estas redes "representan múltiples interpretaciones singulares de la totalidad histórico social de una región, de un país, de una época" y acercarnos a su estudio, hacerlas contenido y, más que eso, productores de comunicación sería "sumergirnos en la historia real, fundamentalmente la historia de la gente común que marca los destinos de los pueblos, individuos sin rostro definido, gente ordinaria que es la verdadera hacedora de la historia" (Vargas-Arenas y Sanoja, 2013: 147).

El migrante lleva en sí la memoria de su lugar. Adonde llega trata de reorganizar lo que dejó atrás. Sus tradiciones, sus oficios, su talento para la supervivencia. No olvida, trasplanta. 
Siempre que puede, saca a la luz las señas de su lugar de origen, las marcas de su cultura. El migrante está atravesado por un optimismo, una esperanza distinta a la de aquel que nació y pudo crecer en un mismo lugar. El que se mueve, recónditamente busca fundar, y esta energía que se manifiesta en la creación de la comunidad vence los obstáculos que se presentan. A la realidad adversa se le hace frente con un discurso épico, una gesta colectiva y edificante.

La comunicación que describimos tiene una base fundamental: la mujer. Si hay un rasgo definitorio opuesto a la comunicación tradicional en la que prevalecen el varón y su voz, es sin duda la femineidad. La mujer es el actor sensible e inteligente de la migración, de la ocupación, de la fundación del barrio y está detrás y al frente de todos los procesos de organización de la vida comunitaria.

La comunicación popular que hemos descrito se construye a partir de identidades líquidas, propias de gente de aluvión, que se encuentran en un territorio gracias a la activación de redes sociales de cooperación, intercambio y solidaridad, las cuales permiten vencer la precariedad y la incertidumbre. Pero concluimos que el barrio proporciona elementos para la construcción de una sociabilidad más ancha que la de los lazos familiares y más profunda y duradera que las relaciones formales e individuales que impone la sociedad. Si queremos generar un modelo de comunicación que nazca de estos sujetos, que sea participativo y protagónico, que narre la cotidianidad, que sea diversa y multicultural, debemos contar con la mujer, con el indígena ( wayuu), con el migrante y el criollo venezolano, con su hacer y crecer juntos en condiciones adversas pero cargadas de esperanza y futuro. Esta comunicación estará llena de sus voces, de sus rostros y sus sueños.

\section{Bibliografía}

Álvarez, R. (2004). La dinámica migratoria colombo-venezolana: Evolución y perspectiva actual. Revista Geoenseñanza, 9(2), pp.191-202.

Ametrano, L. (1995.) El barrio: lugar de encuentros y desencuentros. En Gravano, A. (Comp.). Miradas Urbanas Visiones Barriales. Montevideo, Uruguay: Nordan Comunidad.

Bauman, Z. (2004). La modernidad líquida. Argentina: Fondo de Cultura Económica.

Clavijo, A. (1995). Articulación de las punteras políticas al barrio: ¿lugar conquistado lugar concedido? En Gravano, A. (Comp.). Miradas Urbanas Visiones Barriales. Montevideo, Uruguay: Nordan Comunidad.

Bordieu, B. (2008). El sentido práctico. España: Siglo XXI.

Connolly, P. (s/f). La ciudad y el hábitat popular: Paradigma latinoamericano. Recuperado de http://www.ungs.edu.ar/catedrasur/wp-

content/uploads/2012/11/12_CONNOLLY_VF.pdf 
Díaz-Polanco, H. (2008). Elogio de la diversidad. Globalización, multiculturalismo y etnofagia. La Habana, Cuba: Casa de Las Américas.

Dussel, E. (2007). Para una erótica latinoamericana. Caracas: El Perro y La Rana.

Gómez, A. (2008). La diáspora colombiana: trabajo apreciado y trabajadores despreciados. Ensayos de economía, 33, pp. 15-45.

Hurtado Salazar, S. (1996). La definición sociopolítica del barrio urbano. En Bolívar, T. y Baldón, J. (Comp). La cuestión de los barrios. Caracas: Monte Ávila.

Krippendorf, K. (1990). Metodología de Análisis de Contenido. Teoría y Práctica. Buenos Aires: Paidós.

Ley especial de regularización integral de la tenencia de la tierra de los asentamientos urbanos populares. (2006). República Bolivariana de Venezuela. Recuperado de http://www.acnur.org/t3/fileadmin/Documentos/BDL/2008/6650.pdf?view=1

Mertins, G. y otros (1998). Tenencia de la tierra en áreas de asentamientos informales en ciudades grandes de países en desarrollo. Facultad de Geografía de la PhilippsUniversität de Marburg. Recuperado de http://www.institutodeestudiosurbanos.info/dmdocuments/cendocieu/coleccion_digital/A sentamientos_Informales/Tenencia_Tierra_Areas-Mertins_G.pdf

Spicker, P. y otros (2009). Pobreza: un glosario internacional. Buenos Aires, CLACSO.

Ojeda, N. F. Autoliberación, revolución interna desde lo colectivo. Caracas: El Perro y La Rana.

Ontiveros Acosta, T. y De Freitas Taylor, J. (1996). Repensando el barrio: papel del antropólogo en la rehabilitación de los espacios autoproducido. En Bolívar, T. y Baldón, J. (Comp). La cuestión de los barrios. Caracas: Monte Ávila.

Ornés, S. (2009). El urbanismo, la planificación urbana y el ordenamiento territorial desde la perspectiva del derecho urbanístico venezolano. Revista Politeia, 32(42), Instituto de Estudios Políticos, UCV, pp. 197-225.

Rusque, A. M. (2003). De la diversidad a la unidad en la investigación cualitativa. Caracas: Vadell Hermanos Editores.

Trigo, P. (2008). La cultura del barrio. Caracas, Venezuela: Centro Gumilla-UCAB.

Vargas-Arenas y Sanoja, M. (2013). Historia, Identidad y Poder. Caracas: Editorial Galac.

Yicón, L. y Acosta, N. (2009). Red social de inmigrantes colombianos y concentración urbana. Caso: municipio Maracaibo. Espacio Abierto Cuaderno Venezolano de Sociología. 18(1), pp. 151-174. 